\title{
Globalization: Current Constraints and Promising Perspectives
}

\author{
Socorro Herrera \\ Kansas State University
}

Recent statistics indicate that more than 200 million people worldwide live in a country other than the one in which they were born, with more than a third having moved from an underdeveloped to a developed country and at least another third having moved from one developed nation to another. Although the United States is the world leader as a host country, Europe's migrant population in 2005 exceeded that of North America by almost 50 percent and Western Asia's share of the world's migrants now exceeds 25 million (United Nations, 2011). Most pronounced is an unprecedented migration of persons to the developing world that is both a cause and a consequence of globalization.

\section{Globalization}

At perhaps its most basic level, globalization is the acceleration and intensification of interaction and integration among the people, businesses, and governments of different nations. In a variety of ways, the process of globalization has impacts on human well-being (including health and personal safety), on the environment (water - either too much or too little - is a key factor in global migrations), on culture (including ideas, religion, and political systems), and on the economic development of persons and societies across the world.

\section{Three Challenges of Globalization for Educators}

Adapting to globalization poses monumental challenges for $\mathrm{K}-12$ teachers and teacher educators. Their reactions to the following three challenges will dramatically influence the course of curriculum and instruction in the United States: (1) preparedness for global competition; (2) global competence with diversity; and (3) capacity building for global citizenship. Beyond curriculum and instruction, the extent to which educators succeed in adapting to globalization may determine the future quality of life in the United States. As I will discuss, each challenge already involves a pattern of current constraints on educator ability to address each challenge and, at the same time, has the possibility of opening the door to promising perspectives for critical thinking about and changes in the future for teaching and teacher education in diverse schools and classrooms.

\section{Challenge One: Preparedness for Global Competition}

Challenge one for educators is predicated on the position that today's teachers must prepare globally competitive entrepreneurs (Stewart, 2007; Zhao, 2010). As 
Thomas Friedman, the author of the New York Times best seller The World is Flat has cautioned, "People in India and China are starving for your job" (as cited in Pink, 2005, p. 2). Tomorrow's high school graduate must be prepared to

- sell to the world;

- buy from the world;

- work for international companies;

- manage employees from other cultures and other countries;

- collaborate with people all over the world in joint ventures;

- compete with persons from opposite sides of the globe for jobs and markets; and

- tackle global problems, such as AIDS, avian flu, pollution, and disaster recovery (Center for International Understanding, 2005; Goodwin, 2010; Stewart, 2007).

Critical to attaining these goals for high-school graduates will be their teachers' capacities to maximize school curricula and pedagogy to equip American students with the skills, knowledge, and cross-cultural abilities that enable companies to justify paying higher salaries in the U.S. compared to the salaries of their counterparts in other countries.

Among current constraints associated with this challenge is the trend toward international testing metrics [e.g., Trends in International Mathematics and Science Study (TIMSS) and Programme for International Student Assessment (PISA)] as the best measure of student capacities for competitiveness in a global marketplace. This trend toward international comparisons of student abilities is currently at the heart of educational reforms, which have resulted in curriculum standardization, high-stakes testing, and Science, Engineering, Technology, and Mathematics (STEM) emphases in K-12 Education (Zhao, 2010). For example, comparatively poor performances on international tests have been used by business and political leaders to rationalize proposals for drastic educational reforms including those recommended by the National Governors Association (NGA) in their most recent performance report (NGA, CCSSO, \& Achieve, 2008). However, Zhao (2010) has argued that an inordinate emphasis on international comparisons across students and schools tends to promote both a homogenous curriculum and standardized pedagogies that may not be the best or even the most appropriate solution for every school or school system in the preparation of globally competitive graduates.

Promising perspectives that offer alternatives to homogenization and standardization as a means to global competitiveness instead tend to capitalize upon students' strengths to develop unique and diverse talents. These alternate perspectives encourage the development of students' competences and capacities for entrepreneurship, creativity, critical thinking, global competences, and a variety of other abilities and skills not emphasized in extant curricula and testing (Goodwin, 2010; Pink, 2005; Trilling \& Fadel, 2009). This type of capacity building is consistent with global 
learning for emergent shifts from production-driven toward knowledge-based economies around the globe.

In this issue of the Journal of Curriculum and Instruction, Gillian Roehrig and her colleagues caution that sizeable inequalities among K-12 students in mathematics and science achievement metrics (as frequently utilized by certain STEM initiatives) disadvantage students' career choices and economic futures in global competition (Roehrig, Campbell, Dalbotten, \& Varma, 2012). In an increasingly knowledge-based economy, certain culture-bound ways of knowing (e.g., American Indian) are not appreciated and are not reflected in the outcomes of particular STEM and other internationalized metrics of achievement. In contrast, the inquiry-based approach to learning for which Roehrig and her associates advocate is substantively indicative of promising new perspectives on the educational challenge of preparedness for global competition. Specifically, this approach manages to capitalize upon students' cultural strengths in order to appropriately develop their unique and culturally molded talents. Students whose ways of knowing are respected and appreciated may bring fresh new perspectives on, and innovative ideas about, ways to address complex multinational problems, such as global climate change.

\section{Challenge Two: Global Competence with Diversity}

Challenge two for educators invokes persistent arguments, which stress that tomorrow's graduates and their teachers must exhibit global competence with diversity. In the United States, 25 percent of children under age 18 have a foreign-born parent (Kandel, 2011). This population is growing far more rapidly than the native-born population. Between 2000 and 2008, the foreign-born made up 30 percent of the total U.S. population increase and almost all of the 25-54 working-age group increase (Kandel, 2011). About 30 percent of the foreign-born have arrived in the United States since 2000. This phenomenon is not limited to the U.S.; the demand for global competence with increasing diversity is no less urgent throughout the world. For example, Europe's migrant population of 64 million was (at the regional level) almost fifty per cent greater than the 45 million in North America (Kandel, 2011). Western Asia, with its oil producing nations, also hosts a considerable share of the world's migrants, totaling more than 22 million.

As a result of these worldwide trends, the demand for global competence with diversity, among both graduates and teachers, has never been higher. Schools, communities, businesses, and universities need professionals who are cross-culturally sensitive and linguistically competent with other languages. For many economists, business leaders, professionals, and scholars, foreign language proficiency and a deep understanding of other cultures is an essential ingredient of global competence (Goodwin, 2010; National Career Development Association, 2012; Stewart, 2007; Trilling \& Fadel, 2009; Zhao, 2010). 
A wide variety of educational policies and practices in the United States tend to constrain teachers' capacities to respond to this challenge. For example, among current constraints are national education agendas. No Child Left Behind (NCLB, 2001), with its persistent and long-term emphases on reading and mathematics, has often resulted in curricula that de-emphasize courses that create opportunities for preparing students to understand the cultures of the world, including geography, social studies, and history (Abedi, in press). Similarly, most American school systems do not offer foreign language classes until students reach high school age. This is true despite the fact that these classes tend to increase student interests in, and knowledge about, other cultures and ways of knowing, particularly when delivered at a young age (Curtain \& Dahlberg, 2004).

One promising perspective on the urgent need for global competence with diversity among U.S. graduates and their teachers is exemplified by House Resolution 6036, $111^{\text {th }}$ Congress: Excellence and Innovation in Language Learning Act (Jackson, Kolb, \& Wilson, 2011). To better understand this alternative viewpoint, consider a class of children entering kindergarten in the United States. Although their classes may include students from across the world, lessons that explore global issues and cultures will not typically be incorporated into their schoolwork. They are likely to study only one language-English - until high school, even though they could acquire a second language far more easily if they began their studies in elementary school. In contrast, 20 out of 25 industrialized countries start teaching world languages in grades K-5, and 21 countries in the European Union require nine years of language study (Jackson et al., 2011).

H.R. 6036 would provide school systems greater support and flexibility in the development of programs that would reflect these cross-national patterns in best practice for global and linguistic competence. Specifically the bill would (a) expand the collection and dissemination of information on effective foreign language education, including programs applicable to elementary schools; (b) encourage states to adopt nationally recognized standards for foreign language education and effective assessments that are aligned to such standards; and (c) provide scholarships to students and their teachers for study-abroad opportunities. Although, the bill did not pass its initial vote, it has been referred to committee for amendment and refinement. Irrespective of future outcomes for H.R. 6036, the bill reflects an alternative perspective on, and critical thinking about, new ways to increase global competence for diversity, beginning in the elementary years of schooling.

In this issue of the Journal of Curriculum and Instruction, Murry (2012) presents a very useful heuristic for exploring global competence for diversity among teachers is the Accommodation Readiness Spiral (ARS). This spiral, in conjunction with ecocultural approaches, raises awareness of the value of cross-cultural sensitivity and language competence with students and families from other nations, religions, and societies. 
Rather than conceive of global competence as primarily a concern for teachers, one can argue persuasively that global competence with diversity begins in the home. This is the vital message of the contribution by Byrd (2012) to this issue of the journal. Specifically, teachers benefit in unexpected ways when they embrace the challenge of visiting the home of a student whose culture and language are different than the dominant culture and language of the school. In fact, the Accommodation Readiness Spiral (ARS) highlighted in this issue (Murry, 2012) vividly illustrates the fundamental value of home knowledge to teachers' preparedness for classroom diversity. From home visits, teachers gain a more global perspective on education, as well as knowledge of the home context, family members and relationships, cultural and linguistic ways of knowing, the value that members place on education, and much more.

Yet, as Byrd (2012) points out, such visits are not always accomplished without difficulties. That is not to say, as he illustrates, that teachers may not gain valuable competencies from the management of these complexities. Of particular importance, teachers tend to gain a first-hand appreciation of the way in which students and their guardians respond to educators, view the world, and manage the many obstacles with which they often wrestle on a daily basis.

The teachers' successful delivery of biography-driven instructional (BDI) strategies with culturally and linguistically diverse (CLD) students is a sound indicator of increasing global competence with diversity. Such strategies are in many ways the practical or application side of the ARS. They incorporate what we know about appropriate instructional accommodations of CLD student assets and needs. Highlighted in this issue is the study by Pérez, Holmes, Miller, and Fanning (2012). Their use of BDI strategies offers key evidence that promising new perspectives on teacher preparation and development for global competence with diversity need further attention and study (Pérez, Holmes, Miller, \& Fanning, 2012). The outcomes of this study are especially important to teachers at the secondary level.

\section{Challenge Three: Capacity Building for Global Citizenship}

Challenge three for educators involves the enhancement of efforts to promote capacity building for global citizenship among teachers and students. With respect to global learning and personal development for global competitiveness, it has been argued that U.S. students and teachers should build their capacities to understand and advocate for the global community. With an emphasis in focusing on ways that respect human rights (see Armstrong, 2006; Myers, 2006; Stewart, 2007), it is argued that these capacities are necessary. Despite all of its promise (i.e., to promote cross-cultural and international understandings), globalization carries both positive and negative consequences to different societies and differing sectors of a particular society. For example, efforts to control worldwide pollution may prompt the closing of certain plants or industries in some societies where power production is not yet as technologically efficient as it is in other nations. Among the inconvenient consequences for developing countries may be unemployment, poverty, civil unrest, and more. Capacities for global 
citizenship encourage teachers and students to critically and compassionately explore the interconnectedness and interdependency of peoples, especially the ways that decision making in one society may have profound consequences for others - impacts that are not always intended or appropriately analyzed ahead of policy implementation.

The notion of global citizenship is acknowledged in the United States. There are a number of current constraints on capacity building for global citizenship. First, not everyone agrees on a definition for global citizenship. For some it is more than just caring, but perhaps less than a responsibility. For others, the term inappropriately applies nation-state phenomena to global processes (Rapoport, 2009). Still others wish to relate the idea of a global citizen to habits of mind that seek to preserve a network of relationships and connections across borders, while building a sense of self identity and integrity (McIntosh, 2005). Ultimately, the current absence of a mutually-accepted definition for the term has tended to promote misunderstandings across scholars, teachers and students; conflicts with education constituents; and the politicization of global citizenship.

At the same time, recent emphases on nationalism and patriotism in the wake of the attack on the World Trade Center on September 11, 2011 and the current war in Afghanistan have often tended to foster community resistance toward educational explorations of other societies, alternative forms of government, and global learning (Myers, 2006; Parker, 2011). Rapoport (2009) reports that he was not surprised when his own research found that the social studies standards of only two states mentioned the concept of global citizenship. In addition, the standards for only 15 states referred to the term globalization. Ironically, recent research and analyses indicate that it is citizen attitudes in the United States toward globalization and global learning that continue to markedly constrain both the curricular and instructional efforts of educators to build American teacher and student capacities for global citizenship.

One of the more promising perspectives on global citizenship argues that global citizenaship would connote an allegiance to a global government that does not actually exist (Rapoport, 2009). Instead, global competence is a progressive process of capacity building to live and work anywhere in the world, in ways that exemplify caring and commitment to the collective welfare of the global community. Recent work by Heilman (2008) suggests seven capacities that teachers and students should emphasize in targeting global citizenship

- curiosity (emotional and intellectual openness),

- compassion (sympathetic awareness),

- criticality (judging arguments and making ethical decisions),

- collaboration (structuring shared paths to a common goal),

- creativity (maximizing uniqueness),

- courage (moral strength to persevere), and

- commitment (long-term disposition to monitor and influence). 
For Heilman (2008), this perspective on global citizenship enables students to build capacities that are effectual across subject areas. For example, students who are studying the American Revolution in history might use their emergent capacities for curiosity, criticality, and compassion to connect with students from other former English colonies like India and Jamaica to learn about their countries' experiences with colonization. Students might further explore the implications and impacts of colonization as a recurrent form of cross-cultural, first contact between peoples throughout history. This trajectory on capacity building opens the door for higher-order thinking about issues of sociology and the humanities.

In this issue Levitt and Piro (2012) offer a compelling demonstration of ways in which Gardner's Five Minds for the Future (2008) may be maximized as a framework for capacity building among students that effectively targets this global citizenship. Especially valuable are lessons in globalization skills for American secondary school students. These purposeful rubrics stress that a respectful and ethical mind (Gardner, 2008) directly and indirectly builds those essential student capacities, which Heilman (2008) has associated with development for global citizenship, especially compassion, courage, and commitment.

\section{Conclusion}

In summary, the five articles in this issue address each of the three major challenges of globalization for educators. Particular attention is devoted to perhaps the most relevant challenge of curriculum and instruction - global competence with diversity. The future of this nation may depend on the extent to which students acquire the skills, knowledge, and dispositions necessary to become responsible global citizens. Accordingly, educators would do well to clearly define and advance an agenda that prepares youth for global citizenship.

\section{References}

Abedi, J. (in press). Research and recommendations for formative assessment with English language learners. In H. L. Andrade and G. J. Cizek (Eds.), Handbook of formative assessment (pp. 37-66). Albany, NY: SUNY.

Armstrong, C. (2006). Global civil society and the question of global citizenship. Voluntas, 17(4), 349-57. doi:10.1007/s11266-006-9020-6 CrossRef GS SEARCH

Byrd, D. R. (2012). Conducting successful home visits in multicultural communities. Journal of Curriculum and Instruction, 6(1), 43-54. GS SEARCH

Center for International Understanding. (2005). North Carolina in the world: A plan to increase student knowledge and skills about the world. Raleigh, NC: Author. 
Retrieved from http://ciu.northcarolina.edu/wpcontent/uploads/2010/06/NCWorld ActionPlan.pdf

Curtain, H., \& Dahlberg, C. A. (2004). Making the match: New languages for young learners, grades $K-8\left(3^{\text {rd }}\right.$ ed.). New York: Longman.

Excellence and Innovation in Language Learning Act. H.R. 6036, 111th Cong. (2010). Retrieved from http://www.govtrack.us/congress/bills/111/hr6036/text

Gardner, H. (2008). Five minds for the future $\left(2^{\text {nd }}\right.$ ed.). Boston, MA: Harvard Business School Press.

Goodwin, A. L. (2010). Globalization and the preparation of quality teachers: Rethinking knowledge domains for teaching. Teaching Education, 21(1), 19-32. doi: 10.1080/10476210903466901 CrossRef GS SEARCH

Heilman, E. E. (2008). Including voices from the world through global citizenship education. Social Studies and Young Learners, 20(4), 30-42.

Jackson, A., Kolb, C., \& Wilson, J. (2011, January 28). National imperative for language learning. Asia Society. Retrieved from http://asiancorrespondent.com/47220/national-imperative-for-language-learning/

Kandel, W. A. (2011). The U.S. foreign-born population: Trends and selected characteristics (Report No. R41592). Washington, DC: Congressional Research Service.

Levitt, R., \& Piro, J. M. (2012). Time, space, and culture: Diversifying and globalizing "minds." Journal of Curriculum and Instruction, 6(1), 54-71. GS SEARCH

Mclntosh, P. (2005). Gender perspectives on educating for global citizenship. In N. Noddings (Ed.), Educating citizens for global awareness (pp. 22-39). New York: Teachers College.

Murry, K. G. (2012). Cognitive development, global learning, and academic progress: Promoting teacher readiness for CLD students and families. Journal of Curriculum and Instruction, 6(1), 11-24. GS SEARCH

Myers, J. P. (2006). Rethinking the social studies curriculum in the context of globalization: Education for global citizenship in the U.S. Theory and Research in Social Education, 34(1), 370-394. GS SEARCH

National Career Development Association, (2012). Six universal competencies for career success. Retrieved from 
http://associationdatabase.com/aws/NCDA/pt/sd/news article/34201/ PARENT// ayout details $\mathrm{cc} /$

National Governors Association, Council of Chief State School Officers, \& Achieve, Inc. (2008). Benchmarking for success: Ensuring U.S. students receive a world-class education. Washington, DC: National Governors Association. Retrieved from http://www.corestandards.org/assets/0812BENCHMARKING.pdf

No Child Left Behind Act, 20 U.S.C. § 6310 et seq. (2001).

Parker, W. C. (2011). Constructing public schooling today: Derision, multiculturalism, nationalism. Educational Theory, 61(4), 413-442. doi:10.1111/j.17415446.2011.00412.x CrossRef GS SEARCH

Pérez, D., Holmes, M., Miller, S., \& Fanning, C. A. (2012). Biography-driven strategies as the great equalizer: Universal conditions that promote $\mathrm{K}-12$ culturally responsive teaching. Journal of Curriculum and Instruction, 6(1), 25-42. GS SEARCH

Pink, D. H. (2005, May). Why the world is flat. Wired, 13(5). Retrieved from http://www.wired.com/wired/archive/13.05/friedman.html

Rapoport, A. (2009). A forgotten concept: Global citizenship education and state social studies standards. Journal of Social Studies Research, 33(1), 91-112. GS SEARCH

Roehrig, G., Campbell, K., Dalbotten, D., \& Varma, K. (2012). CYCLES: A culturallyrelevant approach to climate change education in native communities. Journal of Curriculum and Instruction, 6(1), 73-88. GS SEARCH

Stewart, V. (2007). Becoming citizens of the world. Educational Leadership, 64(7), 814. GS SEARCH Retrieved from http://www.ascd.org/publications/educationalleadership/apr07/vol64/num07/Becoming-Citizens-of-the-World.aspx

Trilling, B., \& Fadel, C. (2009). $21^{\text {st }}$ century skills: Learning for life in our times. New York: John Wiley.

United Nations. (2011). UN statistics show migration as a dynamic and diversifying force in global development. Retrieved from http://www.un.org/migration/presskit/pressrelease12sept.pdf

Zhao, Y. (2010). Preparing globally competent teachers: A new imperative for teacher education. Journal of Teacher Education, 61(5), 422-431. doi:10.1177/0022487110375802 GS SEARCH Retrieved from http://jte.sagepub.com/content/61/5/422 


\section{About the Author}

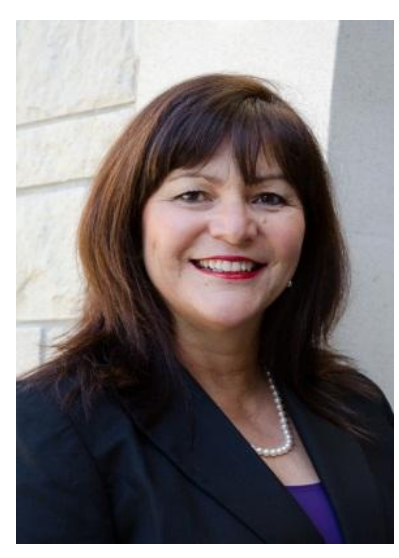

Socorro Herrera, Ph.D., serves as a professor of Elementary Education at Kansas State University and directs the Center for Intercultural and Multilingual Advocacy (CIMA) in the College of Education. Her K-12 teaching experience includes an emphasis on literacy development. Her research focuses on literacy opportunities with culturally and linguistically diverse students, reading strategies, and teacher preparation for diversity in the classroom.

Dr. Herrera has authored several books including Assessment Accommodations for Classroom Teachers of Culturally and Linguistically Diverse Students $(2007,2013)$, Crossing the Vocabulary Bridge:

Differentiated Strategies for Diverse Secondary Classrooms (2011), Mastering ESL and Bilingual Methods: Differentiated Instruction for Culturally and Linguistically Diverse Students (2005, 2011), Biography-Driven Culturally Responsive Teaching (2010), and Teaching Reading to English Language Learners: Differentiated Literacies (2010). Dr. Herrera has authored articles for numerous nationally known journals such as the Bilingual Research Journal, Journal of Hispanic Higher Education, Journal of Research in Education, and the Journal of Latinos and Education. In addition to her writing, Dr. Herrera conducts multi-state professional development on issues of instruction and assessment with CLD students. E-mail: sococo@ksu.edu 